\title{
GmWRKY40, a member of the WRKY transcription factor genes identified from Glycine max L., enhanced the resistance to Phytophthora sojae
}

\author{
Xiaoxia Cui, Qiang Yan, Shuping Gan, Dong Xue, Haitang Wang, Han Xing, Jinming Zhao* and Na Guo*
}

\begin{abstract}
Background: The WRKY proteins are a superfamily of transcription factors and members play essential roles in the modulation of diverse physiological processes, such as growth, development, senescence and response to biotic and abiotic stresses. However, the biological roles of the majority of the WRKY family members remains poorly understood in soybean relative to the research progress in model plants.

Results: In this study, we identified and characterized GmWRKY40, which is a group IIc WRKY gene. Transient expression analysis revealed that the GmWRKY40 protein is located in the nucleus of plant cells. Expression of GmWRKY40 was strongly induced in soybean following infection with Phytophthora sojae, or treatment with methyl jasmonate, ethylene, salicylic acid, and abscisic acid. Furthermore, soybean hairy roots silencing GmWRKY4O enhanced susceptibility to $P$. sojae infection compared with empty vector transgenic roots. Moreover, suppression of GmWRKY40 decreased the accumulation of reactive oxygen species (ROS) and modified the expression of several oxidation-related genes. Yeast two-hybrid experiment combined with RNA-seq analysis showed that GmWRKY40 interacted with 8 JAZ proteins with or without the WRKY domain or zinc-finger domain of GmWRKY40, suggesting there were different interaction patterns among these interacted proteins.

Conclusions: Collectively, these results suggests that GmWRKY4O functions as a positive regulator in soybean plants response to $P$. sojae through modulating hydrogen peroxide accumulation and JA signaling pathway.
\end{abstract}

Keywords: Glycine max (L.) Merr, Phytophthora sojae, GmWRKY40, RNA interference, Yeast two-hybrid, Soybean hairy roots

\section{Background}

Phytophthora spp. are oomycetes that cause devastating diseases on a number of important crops. For example, the pathogen Phytophthora infestans was responsible for a devastating outbreak of potato blight in Ireland [1]. Phytophthora sojae is the second most destructive pathogen of soybean could led to Phytophthora root and stem rot (PRR), causing annual losses of approximately 1-2 billion US dollars globally [2]. P. sojae is widespread, occurring in all major soybean growing regions. PRR can

\footnotetext{
* Correspondence: jmz3000@njau.edu.cn; guona@njau.edu.cn National Center for Soybean Improvement, Key Laboratory of Biology and Genetics and Breeding for Soybean, Ministry of Agriculture, State Key Laboratory of Crop Genetics and Germplasm Enhancement, Nanjing Agricultural University, Nanjing 210095, China
}

cause total loss of the crop in highly susceptible cultivars. Disease resistance breeding is the main strategy to control oomycete diseases. Presently, PRR is mainly managed on the basis of host-mediated resistance provided by resistance $(R)$ genes. In the soybean- $P$. sojae pathosystem, the types of resistance have been described, including race-specific resistance controlled by single dominant Rps (resistance to P. sojae) genes and partial resistance provided by multiple genes [3, 4]. In soybean, $33 R p s$ genes have been identified and mapped to eight chromosomes [5-9]. Among them, Rps1a, Rps1c, Rps1k, $R p s 3 a, R p s 6$, and Rps7 have successively been introgressed in commercial lines [10, 11]. However, resistance genes will be overcome after widespread and persistent

(c) The Author(s). 2019 Open Access This article is distributed under the terms of the Creative Commons Attribution 4.0 International License (http://creativecommons.org/licenses/by/4.0/), which permits unrestricted use, distribution, and reproduction in any medium, provided you give appropriate credit to the original author(s) and the source, provide a link to the Creative Commons license, and indicate if changes were made. The Creative Commons Public Domain Dedication waiver (http://creativecommons.org/publicdomain/zero/1.0/) applies to the data made available in this article, unless otherwise stated. 
infection of pathogens, therefore, their effectiveness is usually transient [12]. Partial resistance is different from Rps-mediated resistance, it is controlled by multiple genes located in multiple loci, and each gene contributing a moderate effect $[13,14]$. It has been shown that partial resistance of soybean can effectively against a variety of pathotypes of $P$. sojae $[15,16]$. Studies on the mechanism of this pathological system have provided evidence for the participation of $R$ gene and constituent part of defense signal pathways [17-19]. Schneider et al. conducted GWA analysis to identify candidate genes and coincident QTLs to investigate the mechanism hypothesis of partial resistance, so as to provide evidence for different hypotheses such as weakened $R$ gene response and some genes that participated in basal defense and signal pathways [20]. Using RNAi approach, soybean GmSGT1 was identified positively contribute to partial resistance and are differently required for soybean Rps1a, Rps1c, Rps1d, Rps1k-mediated disease resistance [21]. Genetic engineering has the potential to confer durable and broad-spectrum resistance on plant by expressing antimicrobial components of known defense signaling pathways [22]. To date, researches have been conducted to increase soybean resistance to $P$. sojae infection by expressing foreign genes which confer resistance to fungal pathogens. Soybean defender against apoptotic death 1 (DAD1), that might participate in the endoplasmic reticulum stress signaling pathway, plays a critical role in defense against Phytophthora pathogens [23]. A soybean novel BTB/POZ domain-containing nuclear protein $\mathrm{GmBTB} / \mathrm{POZ}$ plays a positive role in the soybean response to $P$. sojae [24]. The basic helix-loophelix (bHLH) transcription factor GmPIB1, which repress the expression of GmSPOD 1 by directly bind to its promoter, enhances the resistance of soybean to $P$. sojae [25]. Overexpression of ethylene response factor GmERF5 and GmERF113 increased the soybean resistance to $P$. sojae and positively regulated the expression of the pathogenesis-related genes [26, 27].

Transcriptional regulation of gene expression is mainly mediated by trans-acting sequence specific DNA binding TFs specific recognition cis-acting promoter elements $[28,29]$. DNA binding proteins containing WRKY domains are one of several transcription factor families associated with plant defense responses $[30,31]$. WRKY TFs presence of one or two conserved WRKY domains with about 60 amino acid, these domains followed by a $\mathrm{Cys}_{2} \mathrm{His}_{2}$ or

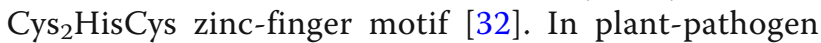
interaction, WRKY TFs involved in the regulation of plant defense mechanisms (PTI and ETI) by recognizing and binding to the W-box or W-like box-type cis elements or other cis elements in promoter regions of some genes [33, 34]. Such as Arabidopsis
WRKY18, WRKY33, and WRKY40 bind to W-box [TTGAC $(\mathrm{C} / \mathrm{T})]$ motif during early MAMP-triggered immunity [35]; OsWRKY51 bind to the cis-element W-box and WLE1 [(T)TGACA] on the promoter of the defense gene OsPR10a, enhances plant resistance to Xoo by activating the expression of this gene [36]. The first WRKY protein SPF1 was cloned from sweet potato in 1994, so far, a growing number of WRKY genes have been identified in various plant species, such as at least 72 members in Arabidopsis thaliana [31], 109 in rice [37] and 182 in soybean [38]. Loss-of-function and gain-of-function studies have demonstrated that WRKY transcription factors act in a complex signaling network as both positive and negative regulators of disease resistance [31, 39, 40]. A number of studies have shown that WRKY TFs have regulatory functions in plant defense responses to various pathogens infection. For example, in Arabidopsis, overexpression of AtWRKY18 and AtWRKY70 results in increased resistance to Pseudomonas syringae and enhanced expression of SAresponsive pathogenesis-related (PR) genes [39, 41]. Furthermore, Arabidopsis WRKY33 is essential for defense toward the Botrytis cinerea, and genes involved in SA signaling, ethylene-JA-mediated crosscommunication and camalexin biosynthesis were identified as direct targets of AtWRKY33 [42]. In rice, overexpression of OsWRKY45 led to enhanced resistance to Magnaporthe grisea, and OsWRKY45 is proposed play a important role in Benzothiadiazoleinduced and SA-mediated defense signaling in rice [43]. Overexpression of OsWRKY6 in Arabidopsis exhibited increased disease resistance to Xanthomonas oryzae through the induction of defense-related genes such as PR1, PDF1, NPR4 and glucanase [44]. Overexpression of pepper CaWRKY4O in tobacco enhanced resistance to Ralstonia solanacearum and modified the expression of hypersensitive response (HR)-associated and pathogenesis-related genes [45]. Members of the genus Phytophthora are among the most serious threats to agriculture and food production, causing devastating diseases in hundreds of plant hosts [46]. Recently WRKY TFs participate in plant-Phytophthora interactions has been further studied. Adachi et al. identified that WRKY TFs phosphorylated by MAPK play important roles in RBOHB-dependent ROS burst and cell deathmediated immunity to Phytophthora infestans in Nicotiana benthamiana [47]. Potato StWRKY8 positively regulate the Arabidopsis resistance to $P$. infestans by interacting with the promoters of benzylisoquinoline alkaloids biosynthetic genes [48]. In Solanum pimpinellifolium, Eight WRKY TFs were identified in $S$. pimpinellifolium-P. infestans interaction and transgenic 
tomato overexpressing $S p W R K Y 3$ showed a significant resistance to $P$. infestans [49]. Overexpression of SpWRKY1 in tobacco conferred resistance to $P$. nicotianae infection [50].

Soybean (Glycine max (L.) Merr.) is a leguminous crop with great economic and agricultural importance all over the world. To date, only a small number of WRKY TFs in soybean have been cloned and functionally characterized. The role of WRKY TFs in abiotic stress responses and growth and development in soybean has been identified. Overexpressing GmWRKY21 or GmWRKY54 enhances cold, salt and drought tolerance in Arabidopsis thaliana, by contrast, it is more sensitive to salt and mannitol stress while overexpressing GmWRKY13 [51]. Virus-induced silencing of GmWRKY58 or GmWRKY76 resulted in a reduction of leaf expansion and termination of stem growth [52]. WRKY-related protein GmWRP1 not only plays an important roles in leguminous plant symbiosis, but also important in the growth and development of leguminous [53]. However, only a few have been characterized in biotic stress responses. It was reported that overexpression of GmWRKY31 enhanced resistance to $P$. sojae, while silencing the same gene enhanced susceptibility [54]. In the present study, the function of GmWRKY40, a putative Group IIc WRKY gene, was characterized, and the gene expression patterns in response to different stress conditions were analyzed. Transgenic soybean hairy roots silencing GmWRKY4O increased susceptibility to $P$. sojae. Moreover, lower levels of ROS was observed in GmWRKY4O-RNA interference roots. Further analysis indicated that GmWRKY40 physically interacted with JAZ proteins. These results suggest that GmWRKY4O functions in soybean response to $P$. sojae through modulating ROS accumulation or JA signaling pathways, and it is an essential component for soybean against Phytophthora pathogens.

\section{Results}

Identification and sequence analysis of GmWRKY40

In previous study, we screened for soybean genes that response to $P$. sojae infection by using RNA silencing in soybean cotyledons according to the method of Subramanian et al. [55] and Yan et al. [21]. Among these, silencing of GmWRKY4O in soybean cotyledon displayed enhanced susceptibility to $P$. sojae. Moreover, GmWRKY4O was up-regulated in the leaves of soybean following infection with P. sojae (Fig. 3a), and GmWRKY4O was thus chosen for the further analysis of its role in response to P. sojae. GmWRKY4O is located on chromosome 8, designated with the locus number Glyma.08G143400. GmWRKY40 cDNA is 1296 bp, with a $708 \mathrm{bp}$ open reading frame (ORF), encoding a protein with 235 amino acids. Protein structure analysis revealed that GmWRKY40 harbors an approximate 60amino acid WRKY domain that is composed of the conserved amino acid sequence (WRKYGQK) and a zincfinger motif $\left(\mathrm{C}-\mathrm{X}_{4-5}-\mathrm{C}-\mathrm{X}_{22-23}-\mathrm{H}-\mathrm{X}_{1}-\mathrm{H}\right)$, indicating that GmWRKY40 belongs to Group IIc of the WRKY family [32]. BLASTp analysis revealed that the amino acid sequence of GmWRKY40 had an 90\% sequence identity with the putative WRKY transcription factor 13 (KHN34020.1) from Glycine sojae and probable WRKY transcription factor 13 (XP_020215926.1) from Cajanus cajan, an $83 \%$ sequence identity with the probable WRKY transcription factor 13 (XP_017432586.1) from Vigna angularis, an $62 \%$ sequence identity with the probable WRKY transcription factor 28 (XP_016452899.1) from Nicotiana tabacum and an $49 \%$ sequence identity with the WRKY13 (NP_195651.1) from the Arabidopsis thaliana (Fig. 1). These results indicated that GmWRKY40 is highly conserved in legumes.

\section{Subcellular localization of GmWRKY40}

To confirm its nuclear localization, the construct was generated in which the full ORF of GmWRKY4O was fused in frame to green fluorescent protein (GFP) under the control of the constitutive CaMV $35 S$ promoter, and the $p 35 S$-GFP used as a negative control (Fig. 2a). The fluorescence was observed by confocal microscope with DAPI staining to detect the nuclei. Typical results indicated that the GFP fluorescence and DAPI staining were predominantly localized to the nucleus expressing $35 \mathrm{~S}$ GmWRKY40::GFP, whereas the 35S-GFP control exhibited the fluorescence in both the nuclei and the cytoplasm (Fig. 2b). These suggested that GmWRKY40 protein is localized in the nucleus, and this localization may help us to explore the function of this protein.

\section{Response of GmWRKY40 transcript to P. sojae infection and various exogenous phytohormones}

To examine the effects of GmWRKY4O in response to pathogen defense, the transcript level of GmWRKY4O in the leaves of soybean in response to infection with $P$. sojae, was determined by quantitative real-time PCR (Fig. 3a). Compared with the mock, GmWRKY4O transcripts were up-regulated in leaves at $12-48 \mathrm{~h}$ postinoculation with $P$. sojae, and with a peak at $24 \mathrm{~h}$. The induction of GmWRKY4O transcript suggested that GmWRKY40 may play an important role in plant resistance to oomycete pathogens.

Phytohormones, such as methyl jasmonate (MeJA), ethylene (ETH), salicylic acid (SA) and abscisic acid (ABA), serve as significant signaling molecules in the regulation of plant defense responses to various biotic stresses and play important roles in mediating the expression of downstream defense-related genes [56]. To evaluate the possible roles of GmWRKY4O in the 


\begin{tabular}{|c|c|c|}
\hline GmWRKY40 & MSTTSHPIVHHSLFDEQ $\ldots \ldots$ DQIPT . QRGFFS. FFTN . ITFPPLG $\ldots \ldots \ldots \ldots$ CHQSSIRAFSSIAF. SSLLAIS & 59 \\
\hline GsWRKY13 & MSTTSHSIVHHSLEEEQ $\ldots$. DQMPT . QIGEFP.FETN . .LTEPELG $\ldots \ldots \ldots \ldots$ CHQSSIRAFSSIAFSSSLVIS & 60 \\
\hline AtWRKY13 & . . MGA INQGISLEDESQTVINEINTNHIGEFFSFESHSTLSSSSSSSSSSPSSLVSPFLGHNSINSFLHNNE. SSEISH & 76 \\
\hline NtWRKY28 & 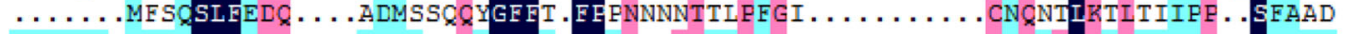 & 55 \\
\hline CCWRKY13 & MSTTSHSIVHFSLFEEQ $\ldots$. DQIFS. QMGEFF.FETN . ITERELG $\ldots \ldots \ldots \ldots$ CHQSSIRAFSSVAF. Z SLAIS & 59 \\
\hline VaWRKY13 & 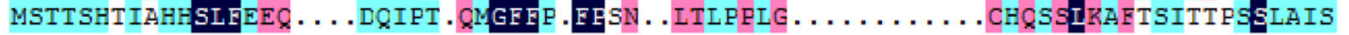 & 60 \\
\hline Consensus & gff $\mathrm{fp}$ & \\
\hline GMWRKY40 & QQDSASNLT . .AETIFSTTAQRSRED . . . . . ITSS . FGGGQFISLHRSSVNAWRLGEVAECFSSKRS . . . . . & 118 \\
\hline GsWRKY13 & QQDSVSNLT . .AETIFSTTAQRSRED $\ldots \ldots$ ITSS. FRGAQFISIHRLSVNAWILGEVADCESCKRS $\ldots \ldots$ & 119 \\
\hline AtWRKY13 & PQDSINLMTNLPEIIISSISSSRQRDDHDGFINLDHHRLTGSISSQRELSNEWZWSCQAGYGSSQRNNHGSEIDV & 156 \\
\hline NtWRKY28 & N. $\ldots \ldots \ldots$ NSIIESTALRQKED $\ldots \ldots$ ITTSIFGGPHLISIQRATZNTWZWGEVNERSNVRRSRL $\ldots \ldots$ & 108 \\
\hline CCWRKY13 & QQDSASNLT $\ldots$. ETIFSTTAQRSRED $\ldots . .$. INSTT FGGAQFISIQRSSVNFWRPGEVTDCFSTKRS $\ldots \ldots$ & 118 \\
\hline VaWRKY13 & QQDSSTSNL $\ldots$ TEIIFHKSTST $\ldots \ldots \ldots \ldots \ldots$ FGGAQFISIHRSSINEWZLGEVSDCFGSKRS $\ldots \ldots$ & 111 \\
\hline Consensus & $\bar{s} \quad \bar{n} \overline{w a}$ & \\
\hline GMWRKY40 & 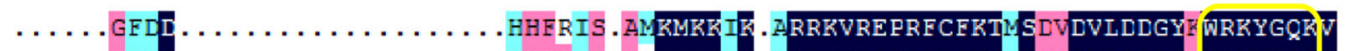 & 170 \\
\hline GsWRKY13 & $\ldots \ldots \ldots \ldots \ldots$ HHLGIS.ATKMKKIK. RRRKVREPRFCFKM SDMDVLDDGYF WRKYGQKV & 171 \\
\hline AtWRKY13 & RHHHHDTPSRHDKHNTASIGVVSSIKMKKIK. TRRKVREPRECFKTISEVDVLDDGYF WRKYGQKV & 235 \\
\hline NtWRKY28 & $\ldots \ldots \ldots \ldots \ldots$ DHLGVS.AIKMKKMRSSRRKVREPRFCFKTISLVDVLDDGYF WRKYGQKKV & 161 \\
\hline CCWRKY13 & . .HHLGIS.AMKMKKM . IRRKVREPRFCFKTMSDVDVLDDGYWWRKYGQKV & 170 \\
\hline VaWRKY13 & 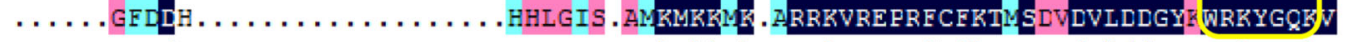 & 164 \\
\hline Consensus & kmkk $k$ rrkvreprfcfkt $s$ dvlddgy wrkyggkv & \\
\hline GminKY 40 & 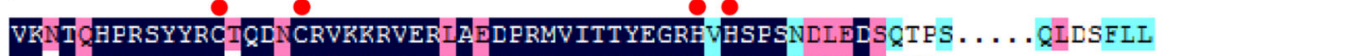 & 234 \\
\hline GsWRKY13 & VKSTHHPRSYYRQIQDIXCRVKKRVER FZIDERUVITTYEGRHVHSPSNDLEDSIST $\ldots \ldots \ldots \ldots$ & 227 \\
\hline AtWRKY13 & VKITOHPRSYYRCTQLKCRVKRRVEEIZIDPRMVITTYEGRHIHSPSNHLDLDSLSTSHLHPEISNF FW & 304 \\
\hline NtWRKY28 & VKNTCHFRSYYRCTQDNCRVKKRVERIZEDPRMVITTYEGRHVHSPSLDEEDSQASS . . . . CINNLLW & 225 \\
\hline CcWRKY13 & VKN TCHFRSYYROIQDNCRVKKRVERIZEDPRMVITTYEGRHZHSFSSDLEDSOTLS ..... QIGNELW & 234 \\
\hline VaWRKY13 & VKNTCHPRSYYRCTQDNCRVKKRVERIZEDPRMVITTYEGRHVHSPSNDLEDSSSPS $\ldots . .$. QIGNELW & 228 \\
\hline Consensus & $\overline{v k} \bar{t}$ hprsyyrc gd crvkkrver a dprnvittyegrh hsps $\bar{d}$ & \\
\hline \multicolumn{3}{|c|}{$\begin{array}{l}\text { Fig. } 1 \text { Characterization and sequence analysis of GmWRKY40. Sequence alignment of the deduced GmWRKY40 protein with Glycine sojae WRKY13 } \\
\text { (KHN34020.1), Cajanus cajan WRKY13 (XP_020215926.1), Vigna angularis WRKY } 13 \text { (XP_017432586.1), Nicotiana tabacum WRKY } 28 \\
\text { (XP_016452899.1) and Arabidopsis thaliana WRKY13 (NP_195651.1). The dark blue (100\%), pink (80\%), and cyan (60\%) boxes represent levels of } \\
\text { amino acid identity or similarity. The double arrow indicates the WRKY domain. The highly conserved amino acid sequence is boxed. The C and } \\
\text { H residues in the zinc-finger motif are marked by red dots }\end{array}$} \\
\hline
\end{tabular}

signaling cascades utilized by these hormones, GmWRKY40 transcript levels were monitored by qRTPCR in 7-day-old soybean roots treated with MeJA, ETH, SA, and ABA. As shown in Fig. 3b-e, after the $100 \mu \mathrm{M}$ MeJA treatment, GmWRKY4O expression increased within $1 \mathrm{~h}$ to $24 \mathrm{~h}$ post-treatment, with a peak at $6 \mathrm{~h}$ (3.9-fold). In response to $2 \mathrm{mM}$ of ethylene, the GmWRKY40 transcript level was notably enhanced from $1 \mathrm{~h}$ to $24 \mathrm{~h}$. The expression of GmWRKY40 was obviously induced at $6 \mathrm{~h}$ after $5 \mathrm{mM}$ SA treatment and approaching highest (3.4-fold compared with mock) levels at $12 \mathrm{~h}$. Under $50 \mathrm{mM}$ ABA treatment, the expression of GmWRKY4O increased dramatically at $1 \mathrm{~h}$ and reduced to the mock-treated levels at $3 \mathrm{~h}$, then highly induced around $6 \mathrm{~h}-24 \mathrm{~h}$. These results indicated that GmWRKY40 may be involved in pathogen responses through the plant hormones signaling pathways.

\section{Suppression of GmWRKY40 increased soybean susceptibility to $P$. sojae}

In order to evaluate the biological function of GmWRKY40, GmWRKY40 was silenced in soybean hairy roots to tests the effect on resistance. The hairy roots with GFP fluorescence were isolated for assay (Additional file 1: Figure S1A). To confirm the silencing efficiency, we performed quantitative real-time PCR, which showed a significant decrease in the RNAi-GmWRKY40 fluorescent roots compared to the RNAi empty vector control roots (Additional file 1: Figure S1B).

To investigate whether GmWRKY40 participate the resistance of soybean to $P$. sojae, transgenic roots expressing RNAi-GmWRKY40 or RNAi empty vector were infected with $P$. sojae. The Williams 82 roots expressing RNAi empty vector exhibited slightly necrotic HR lesions, while infection of RNAi-GmWRKY4O roots led to a more seriously extended lesions (Fig. 4a-b).

To further analyze the influence of GmWRKY4O to disease resistance in soybean, transgenic roots were inoculated with zoospore suspensions of $P$. sojae strain P6497R, which constitutively expresses red fluorescence protein (RFP). The number of roots that supported hyphae invading into root epidermis and oospore germination and extension at the inoculated area were counted at 24,36 and $48 \mathrm{~h}$ post-inoculation, according to Wong 
A

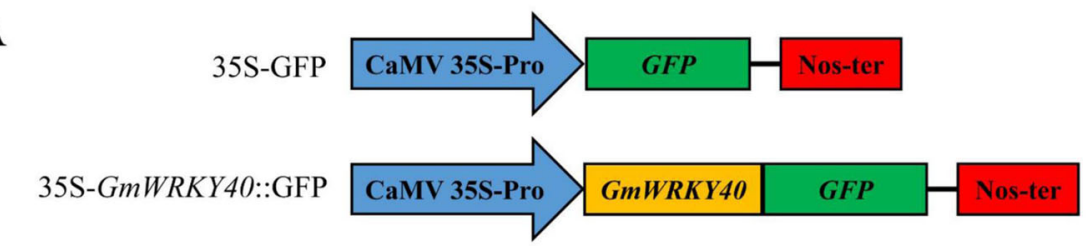

B

GFP

DAPI

Bright

Mergered
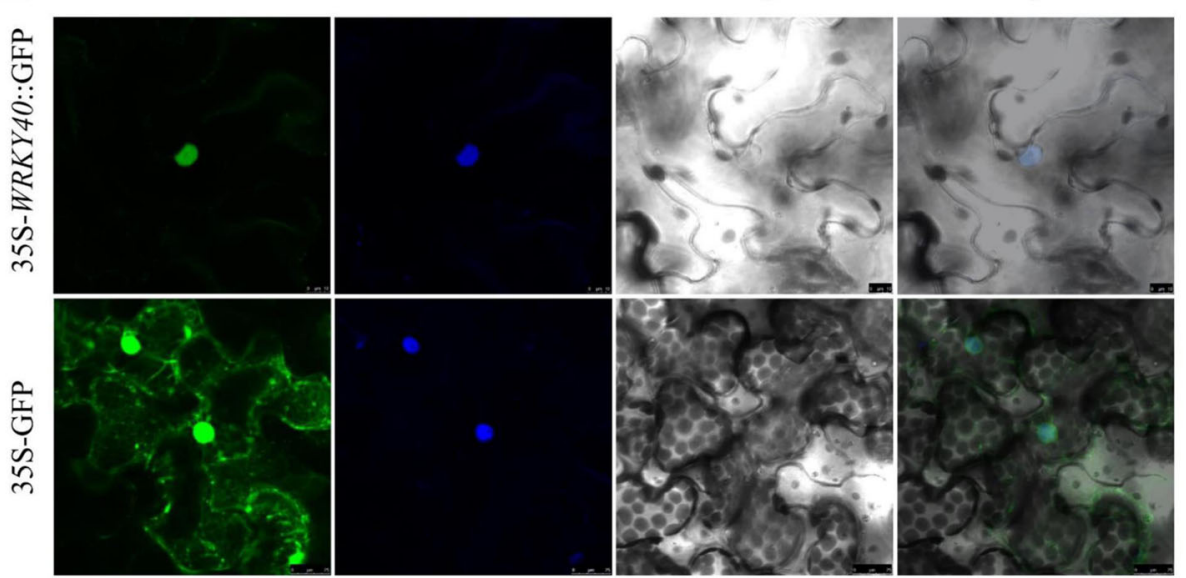

Fig. 2 Subcellular localization of the GmWRKY40 protein. a Schematic diagram of the 35S-GmWRKY40:GFP fusion construct and the 35S-GFP construct. b Agrobacteria carrying 35S-GmWRKY40:GFP and 35S-GFP were infiltrated into leaves of $\mathrm{N}$. benthamiana plants. Pictures were taken in bright and fluorescence fields after DAPI staining with confocal laser scanning microscopy $72 \mathrm{~h}$ after agroinfiltration

et al. [57]. The obviously greater number of inoculated RNAi-GmWRKY4O roots allowed hyphal invasion and oospore development compared to roots that expressing RNAi empty vector indicating that the RNAiGmWRKY40 roots exhibited hyper-susceptibility to $P$. sojae (Fig. 5). We also determined the P. sojae biomass accumulation by quantitative real-time PCR using primers specific to highly conserved repetitive sequences in the $P$. sojae genome. RNAi-GmWRKY40 transgenic roots showed a higher growth rate of $P$. sojae biomass compared with RNAi empty vector (Fig. 4c-d). These results indicated that GmWRKY4O as a positive regulator plays pivotal roles in soybean resistant to $P$. sojae.

\section{Suppression of GmWRKY40 decreased the accumulation of ROS}

Reactive oxygen species (ROS) play vital roles in plant defenses as signaling molecules [58]. To check whether ROS accumulation was relevant to the hyper-susceptibility to $P$. sojae of the soybean, we detected the accumulation of $\mathrm{H}_{2} \mathrm{O}_{2}$ in RNAi-GmWRKY40 transgenic roots and RNAi empty vector roots following exposure to $P$. sojae, showing that significantly decreased $\mathrm{H}_{2} \mathrm{O}_{2}$ production was detected in RNAi-GmWRKY40 roots relative to RNAi empty vector roots (Fig. 6b). The 3, 3' -diaminobenzidine (DAB) staining on the RNAi-GmWRKY40 transgenic roots following $P$. sojae infection exhibited less brown relative to empty vector roots (Fig. 6a), which was consistent with the results measured above.

To explore the underlying mechanism of the reduced $\mathrm{H}_{2} \mathrm{O}_{2}$ levels in the transgenic roots during disease resistance process, the expression of oxidation-related genes in RNAi-GmWRKY4O transgenic and control roots were analyzed in response to $P$. sojae. As shown in Fig. 6c-e, the transcript levels of NADPHox (NADPH oxidase, $\mathrm{H}_{2} \mathrm{O}_{2}$ synthesis-related gene) [59], $A P X 1$ (ascorbate peroxidase 1) and CAT1 (catalase 1) (ROS scavengingassociated genes) $[60,61]$ were not significantly different in RNAi-GmWRKY40 transgenic roots before $P$. sojae infection compared with control roots, showing that GmWRKY40 did not participate in the accumulation of $\mathrm{H}_{2} \mathrm{O}_{2}$ under normal conditions. After inoculation, the expression of GmNADPHox in RNAi-GmWRKY4O transgenic roots was significantly lower than that in the control roots, otherwise, the expression of GmAPX1 related to $\mathrm{H}_{2} \mathrm{O}_{2}$ scavenging was significantly up-regulated, indicating that GmWRKY4O participated in the accumulation of $\mathrm{H}_{2} \mathrm{O}_{2}$ during the $P$. sojae infection by activating the $\mathrm{H}_{2} \mathrm{O}_{2}$ synthesis pathway and inhibition of $\mathrm{H}_{2} \mathrm{O}_{2}$ scavenging.

\section{GmWRKY40 interact with JAZ proteins}

Increasing evidences suggested that WRKY proteins function by forming protein complexes with other interactors [33]. 

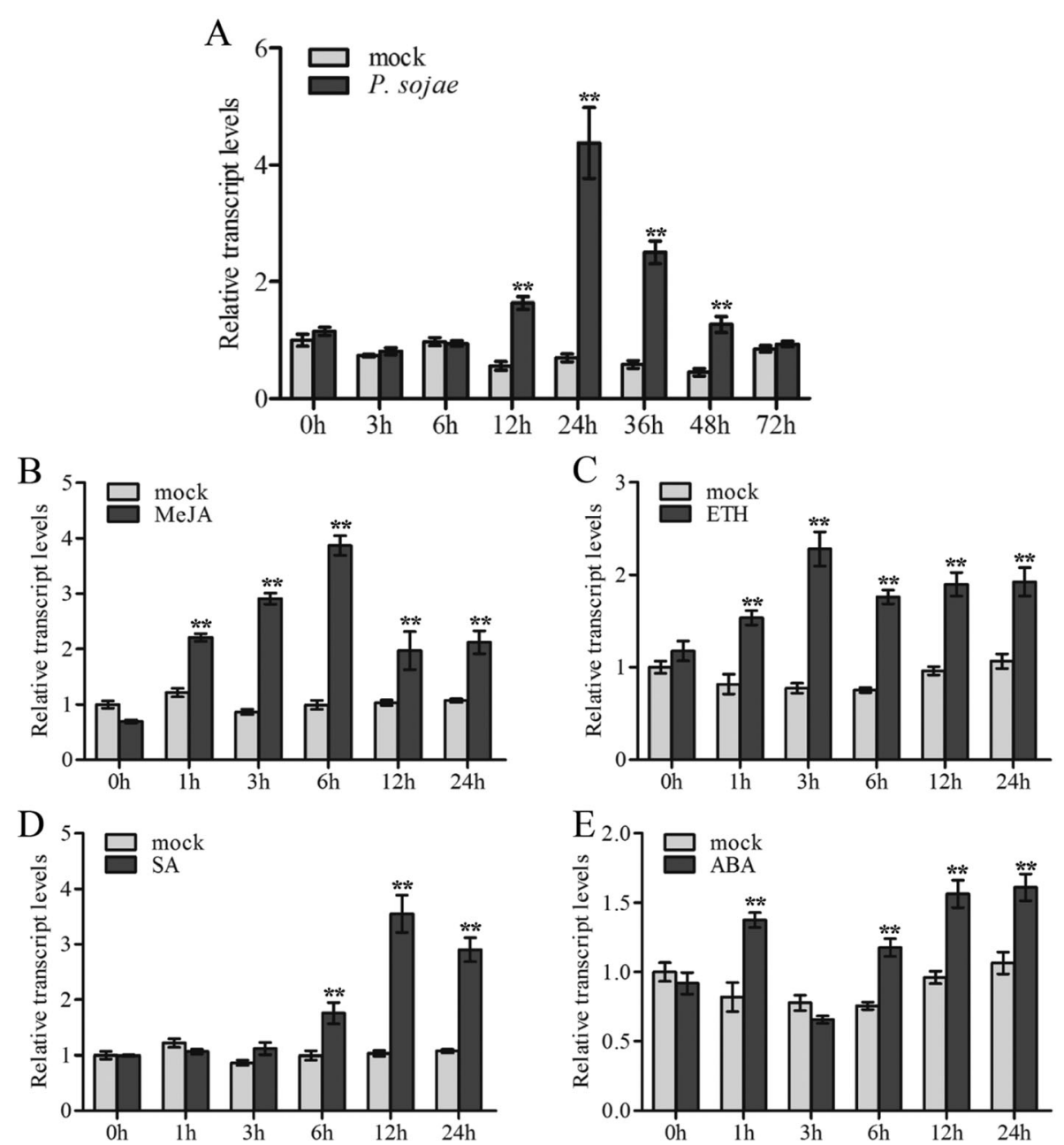

Fig. 3 Expression patterns of GmWRKY40 under diverse stress conditions. Approximately 1-week-old soybean seedlings were used for each of the following treatments. a The relative expression of GmWRKY 40 was determined at different time points in the soybean hypocotyl after inoculation with P. sojae. b-e GmWRKY40 transcripts examined in soybean roots at various time periods after treatment with $100 \mu \mathrm{M}$ MeJA, $2 \mathrm{mM}$ ETH, $5 \mathrm{mM}$ $\mathrm{SA}$ and $50 \mathrm{mM} \mathrm{ABA}$. Error bars indicate the standard error; the experiments were repeated three times along with at least three independent repetitions of the biological experiments. Asterisks indicate statistically significant differences $\left({ }^{* *} P<0.01\right)$

To determine which protein is responsible for the interaction with GmWRKY40, we performed yeast two-hybrid screening to identify GmWRKY40-interacting partners. There are three JAZ proteins (JAZ1-Glyma.07G041400.1, JAZ2Glyma.01G204400.1, and JAZ3-Glyma.09G071600.1) represented among the candidate interactors (Here we temporarily designated JAZ1-JAZ8, including the 5 JAZ proteins mentioned below). To confirm their interaction in yeast, open-reading frame sequences of the eight proteins were fused with the activation domain $(\mathrm{AD})$ of the pGADT7 vector and used for further interaction experiments with GmWRKY40. As shown in Fig. 7b, GmWRKY40 interacted strongly with the three JAZ proteins: JAZ1, JAZ2, and JAZ3. To further examine which domain of GmWRKY40 proteins is critical for the interactions with JAZ1, JAZ2, or JAZ3, pGBKT7 vectors containing a WRKY domain mutant or a zinc-finger domain mutant were used (Fig. 7a). The results showed that JAZ2 exhibited weak interaction with zincfinger domain mutant protein, JAZ1 and JAZ3 exhibited no interactions neither with WRKY domain mutant protein nor with zinc-finger domain mutant protein (Fig. 7b).

To gain further insights into the potential mechanisms of the reduced resistance in GmWRKY40-RNAi transgenic soybean roots, the gene expression between empty vector control and transgenic roots inoculated with P. sojae for 12 $\mathrm{h}$ was determined and compared using RNA sequencing. We detected multiple differentially expressed stressrelevant genes, including $J A Z$ genes, $E R F$ genes, peroxidase genes, transcription factors, and disease resistanceresponsive genes (Additional file 2: Table S1). It was noteworthy that $8 \mathrm{JAZ}$ proteins (Table 1) were induced in GmWRKY40-RNAi transgenic soybean roots after infected 
A

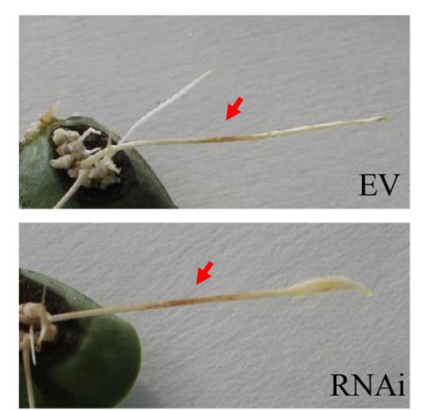

$\mathrm{B}$

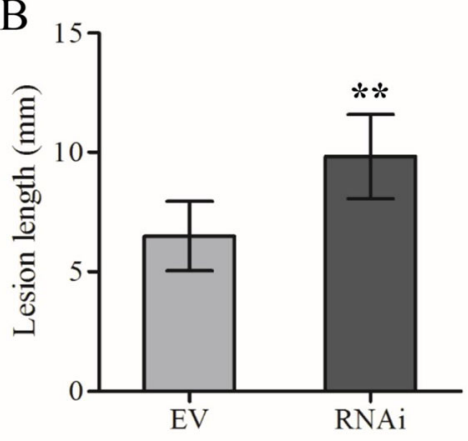

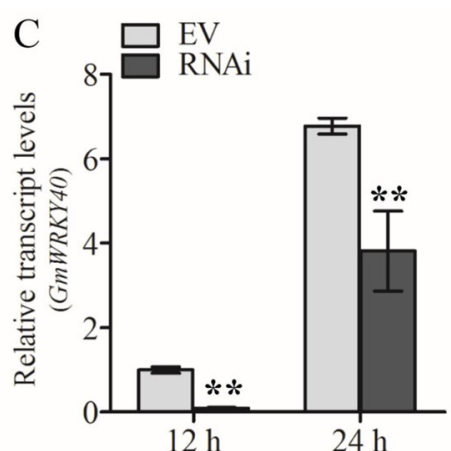

$\mathrm{D} \square \mathrm{EV}$

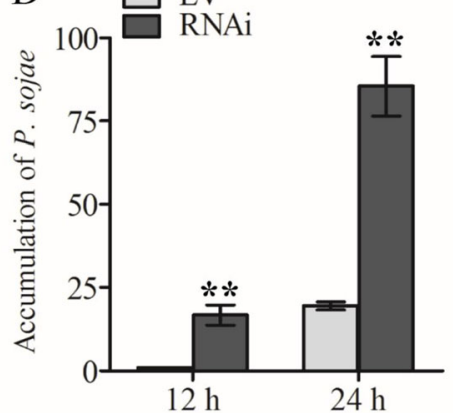

Fig. 4 Transgenic soybean hairy roots with silenced GmWRKY40 exhibit enhanced susceptibility to Phytophthora sojae. a Disease phenotypes of GmWRKY40-RNAi Williams 82 hairy roots and control at $36 \mathrm{~h}$ after inoculated with P6497. b The lesion length of P6497 infected hairy roots. Lesion length was taken 36 hpi. c Relative expression of GmWRKY 40 was determined by qPCR at 12 and 24 hpi in GmWRKY 40 silencing or EV hairy roots (d) P. sojae biomass was determined by qPCR at 12 and $24 \mathrm{hpi}$ in GmWRKY40 silencing or EV hairy roots. The experiments all above were repeated three times along with at least three independent repetitions of the biological experiments. Error bars indicate the standard error. Asterisks indicate statistically significant differences $\left({ }^{* *} P<0.01\right)$

with $P$. sojae, including the previously tested three proteins interacted with GmWRKY40 (Fig. 7b). We further studied the interaction of other 5 JAZ proteins with GmWRKY40, with the result that they are interacted with GmWRKY40 either (Fig. 8). The interaction results of $5 \mathrm{JAZ}$ proteins with domain mutated GmWRKY40 were shown in Fig. 8. WRKY domain of GmWRKY40 is necessary for interaction with JAZ5 (Glyma.16G010000.1) and JAZ7 (Glyma.15G179600.1). JAZ4 (Glyma.13G112000.1), JAZ6 (Glyma.11G038600.1), and JAZ8 (Glyma.17G047700.1) exhibited interact either with WRKY domain mutant protein or with zinc-finger domain mutant protein. The results suggested that there has different interaction patterns when GmWRKY40 interact with different JAZ proteins.

\section{Discussion}

In the plants response to various stresses, some transcription factors were activated and then subsequent a numerous defense-associated genes were transcriptional regulated, these changes are essential for the defense mechanisms establish. Genes respond with coordinated changes in transcriptional expression when the plant exposure to pathogen attack, then led to cellular and physiological reprogramming and the resistance to pathogen infection increasing [62]. Plenty of genes expression changes are regulated by various TFs. A large body of evidences suggests that WRKY TFs play important roles as positive or negative regulators in plant response to pathogen infection [33].

In this study, we performed a functional analysis of the soybean WRKY40 gene, which was demonstrated to increase soybean resistance to $P$. sojae. It was reported that WRKY transcription factors response to biotic stresses in many plant species, including Arabidopsis [42, 63], rice [64, 65], barley [66], cotton [67], pepper [40], and tobacco [47, 68], among others. To our knowledge, a few WRKY transcription factors have been functionally demonstrated in soybean-pathogen interactions. Using virusinduced gene silencing, Pandey AK et al. identified 3 WRKY genes (GmWRKY36, GmWRKY40, and WRKY45) that play a role in Rpp2-mediated resistance toward Phakopsora pachyrhizi [69]. A genome-wide annotation of the soybean WRKY family was carried out and 75 genes were identified as involved in the soybean response to $P$. pachyrhizi infection based on transcriptional regulation [38]. GmWRKY30 and GmWRKY6 play a role in soybean Rsv1-mediated extreme resistance to Soybean mosaic virus [70]. The function of WRKY transcription factor 


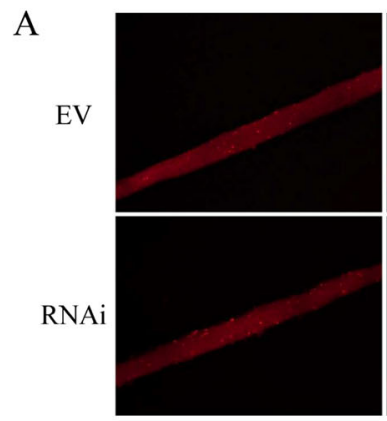

24 hpi

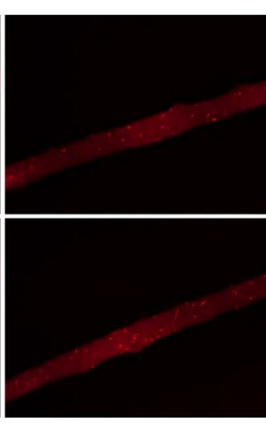

$36 \mathrm{hpi}$

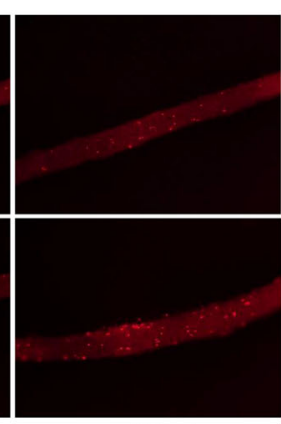

48 hpi

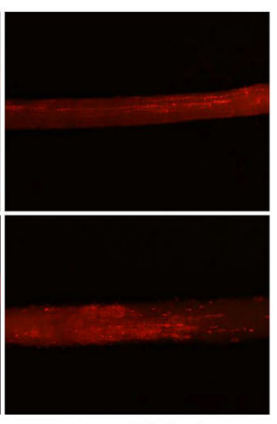

72 hpi

B

\begin{tabular}{|c|c|c|c|c|c|c|}
\hline \multirow{2}{*}{} & \multicolumn{2}{|c|}{$24 \mathrm{hpi}$} & \multicolumn{2}{c|}{$36 \mathrm{hpi}$} & \multicolumn{2}{c|}{$48 \mathrm{hpi}$} \\
\cline { 2 - 7 } & $\mathrm{EV}$ & RNAi & EV & RNAi & EV & RNAi \\
\hline No. of roots infected & $2 / 27$ & $7 / 26$ & $10 / 27$ & $19 / 26$ & $11 / 27$ & $22 / 26$ \\
\hline $\begin{array}{c}\text { No. of roots developed } \\
\text { Oospores }\end{array}$ & $0 / 27$ & $2 / 26$ & $2 / 27$ & $9 / 26$ & $4 / 27$ & $13 / 26$ \\
\hline
\end{tabular}

Fig. 5 GmWRKY40 regulates soybean defense against $P$. sojae infection. a GmWRKY40 silenced hairy roots were hyper-susceptible to $P$. sojae infection. Hairy roots were inoculated with zoospore suspension ( $10^{4}$ zoospore $/ \mathrm{mL}$ ) of the $P$. sojae P6497R. P. sojae infection was monitored using a fluorescent microscope at 24, 36 and $48 \mathrm{hpi}$. Bar equals $0.5 \mathrm{~mm}$. b Infection progress of $P$. sojae in soybean roots expressing EV or RNAiGmWRKY40. The number of roots allowing hyphae penetration or oospore development were counted at 24,36 and 48 hpi. This experiment were repeated three times with similar results

response to $P$. sojae in soybean was characterized as well. Overexpression and RNA interference analysis demonstrated that GmWRKY31 enhanced resistance to $P$. sojae [54]. Lin et al. performed comparative transcriptomic analysis to characterize genes and multiple branches of putative regulatory networks associated with resistance to $P$. sojae in 10 soybean NILs, it is apparent that some of the genes belonging to WRKY family play pivotal roles in defense signaling transduction [71]. Our investigation showed that GmWRKY4O is induced by $P$. sojae infection (Fig. 3a), indicating its potential participation in modulating $P$. sojae. The transgenic roots, which presented decreasing transcripts of GmWRKY40, exhibited hyper-susceptibility to P. sojae (Figs. 4 and 5 ). In this experiment, we also used Williams (lacks any known Rps gene) to examine whether the GmWRKY40 involved in basal resistance to $P$. sojae. The results showed that more serious extended lesions and greater P. sojae biomass accumulation were determined in RNAiGmWRKY40 roots compared with RNAi empty vector roots after inoculated $P$. sojae (Additional file 1: Figure $\mathrm{S} 2$ ). The results show that GmWRKY40 is required for soybean response to $P$. sojae. Moreover, the research about soybean bHLH transcription factor GmPIB1 revealed that overexpression transgenic Williams (rps) hairy roots enhanced the resistance to $P$. sojae, while GmPIB1-RNAi transgenic 'L77-1863' (Rps1b) hairy roots exhibited more susceptibility [25]. In rice, Overexpression of OsWRKY62 reduces the basal defense and Xa21-mediated resistance against Xoo, imply that
OsWRKY62 functions as a negative regulator to Xoo in rice [72]. Here, our results demonstrated that GmWRKY40 acted as a positive regulator in the defense response of soybean to $P$. sojae.

The phytohormones JA, SA, ET, and ABA are important signaling molecules involved in the plant response to pathogen infection [73]. WRKY transcription factor has been revealed function as key components in various hormone signaling pathways [42, 74]. For example, WRKY7O acts as an activator of SA-induced genes and a repressor of JA-responsive genes, indicating that WRKY7O is an important node of convergence integrating SA and JA signaling during plant defense responses [41]. AtWRKY8 is involved in the defense response against TMV-cg through the direct regulation of $A B I 4$, ACS6, and ERF104 and mediates the crosstalk between ABA and ethylene signaling during the interaction between TMV-cg and Arabidopsis [75]. Our present study demonstrated that levels of GmWRKY40 mRNA transcripts were significantly induced by $P$. sojae and diverse hormone signaling molecules stresses (Fig. 3). In addition, we analyzed the expression levels of SA signaling pathway associated genes, including GmNPR1, GmPR1a and GmPR5. It is reveal that GmWRKY4O silencing led to the remarkably decreased GmNPR1, GmPR1a and GmPR5 mRNA levels compared with the control after inoculated with $P$. sojae (Additional file 1: Figure S3). We deduce that GmWRKY40 might be involved in soybean defense responses to $P$. sojae infection through phytohormones-mediated signaling pathways. 


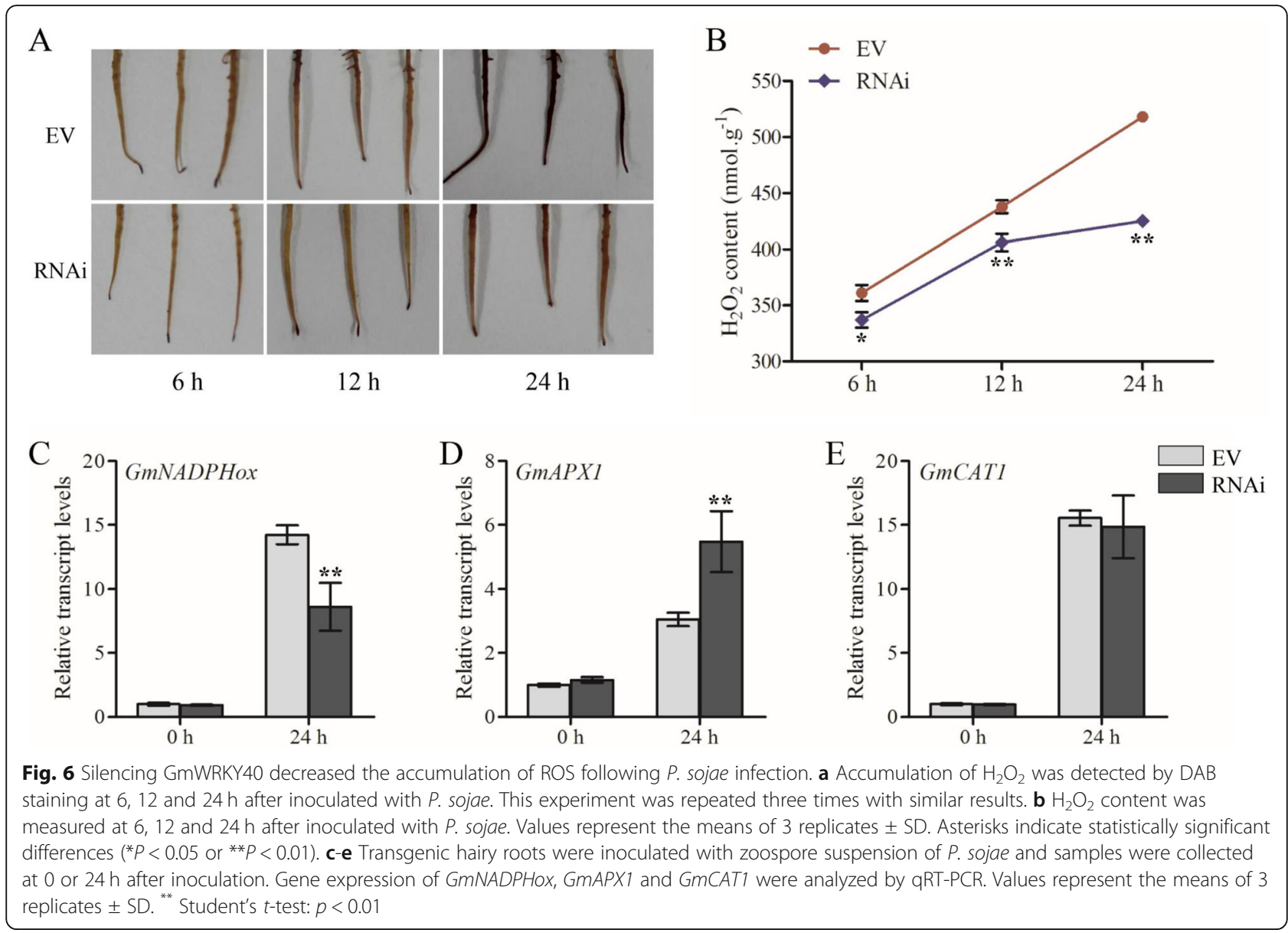

ROS network plays an important role in signal transduction of plant resistance to pathogens $[58,76]$. ROS was rapidly produced following plant infected with pathogen, then preventing pathogen from entering the cell or the resistant genes were induced to inhibit pathogen growth [77, 78]. In plant-pathogen interactions, WRKYs played essential roles either in ROS bursts or in ROS scavenging. Previous work showed that WRKYs phosphorylated by MAPK was required for plant immune ROS bursts by activation of NADPH oxidase in $N$. benthamiana [47]. In our investigation, the lower $\mathrm{H}_{2} \mathrm{O}_{2}$ accumulation was observed in the transgenic roots of RNAi-GmWRKY4O compared with control roots after inoculated with $P$. sojae (Fig. 6a-b). The transcript level of GmNADPHox, which associated with $\mathrm{H}_{2} \mathrm{O}_{2}$ synthesis [79], was detected lower in the RNAi-GmWRKY40 transgenic roots relative to the control roots (Fig. 6c). We reasoned that silencing GmWRKY4O down-regulated the expression of GmNADPHox resulting in reduced $\mathrm{H}_{2} \mathrm{O}_{2}$ accumulation and compromised transgenic soybean roots resistant to $P$. sojae.

JAZ proteins were identified as the transcriptional repressors of JA signaling [80]. Jasmonate treatment causes JAZ degradation and this degradation is dependent on activities of the $\mathrm{SCF}^{\mathrm{COI} 1}$ ubiquitin ligase and the $26 \mathrm{~S}$ proteasome [81], leading to activation of various transcription factors, which subsequently regulate their downstream signal cascades and modulate respective plant responses [82, 83]. Some TFs have been reported as targets of JAZ proteins, such as bHLH TFs, MYB TFs and DELLAs [84]. In this study, we found that GmWRKY40 interacted with several JAZ proteins (Figs. 7 and 8), which are up-regulated in GmWRKY40-RNAi transgenic soybean roots after infected with $P$. sojae (Table 1). JAZ protein has been reported play roles in pathogen defense $[83,85]$. Here we hypothesized that the up-regulation of JAZ proteins in GmWRKY4O silenced transgenic roots enhances susceptibility to $P$. sojae infection by repression of the JA signaling. More work is required to understand the roles of these JAZ proteins in soybean response to pathogens. In addition, WRKY TFs also act on transcriptional level of $J A Z$ genes expression. Jiang and Yu's research showed that WRKY57 acts as transcriptional activator that binds to the promoter sequences of $J A Z 1$ and JAZ5 to compete with the transcription regulation function of WRKY33, coordinate regulate Arabidopsis against $B$. cinerea [86]. We also tested which domain of GmWRKY40 responsible for the interaction with JAZ proteins. WRKY domain of GmWRKY40 is necessary for 


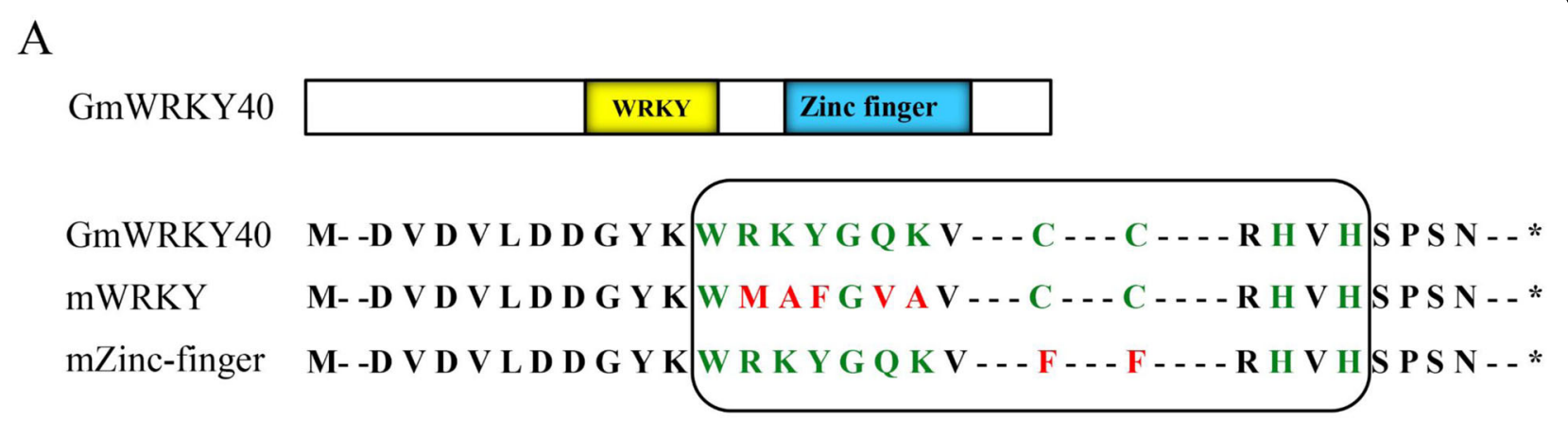

B

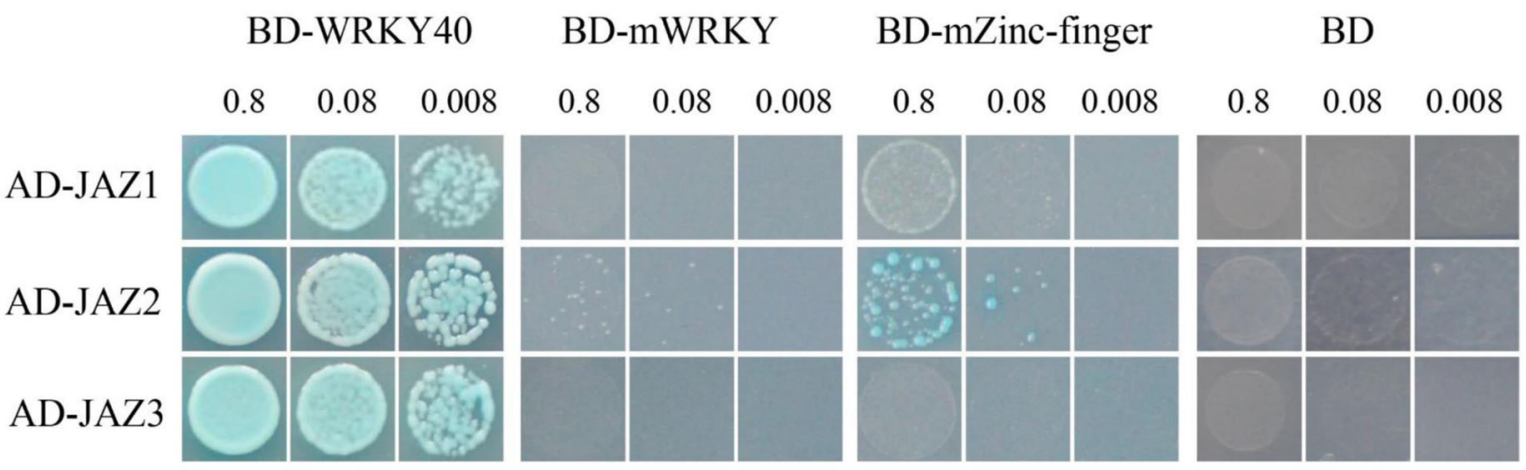

Fig. 7 GmWRKY40 interacts with JAZ proteins. a Diagram of the GmWRKY40 protein functional domains and schematic of the amino acid mutation of WRKYGQK domain or Zinc finger domain. mWRKY indicate WRKY domain mutation; mZinc-finger indicate Zinc-finger domain mutation. b Yeast-two-hybrid assays. The Gal4 DNA binding domain was fused with GmWRKY40 (shown as BD-WRKY40, BD-mWRKY or BD-mZincfinger) and the Gal4 activation domain was fused with JAZ1, JAZ2 or JAZ3 (shown as AD-JAZ1, AD-JAZ2 or AD-JAZ3). The Gal4 DNA binding domain expressed by pGBKT7 was used as a negative control. $0.8,0.08$, and 0.008 are the bacteria diluted concentration gradient

JAZ2/5/7-GmWRKY40 interaction, however JAZ4/6/8 exhibited interact both with WRKY domain mutant and zincfinger domain mutated protein. JAZ1/3 had no interactions neither with WRKY domain mutant protein nor with zincfinger domain mutant protein (Figs. 7 and 8). Thus, the WRKY domain and zinc-finger domain of GmWRKY40 protein was needed differently for the interaction with different JAZ proteins. The function of these JAZ proteins in soybean response to $P$. sojae and the mechanisms of diverse JAZ proteins interact with different domain mutated
GmWRKY40 will be addressed in future studies to elucidate the underlying of GmWRKY40-mediated regulation in the soybean defense response.

\section{Conclusions}

Collectively, the data presented in this study not only reveal an important regulatory function for GmWRKY40 in soybean resistance to $P$. sojae, but also provide a foundation for further investigation of $P$. sojae-induced signaling pathways in which GmWRKY4O participates.

Table 1 RNA sequencing analysis of JAZ genes up-regulated in GmWRKY40-RNAi transgenic roots compared with EV soybean roots

\begin{tabular}{|c|c|c|c|c|}
\hline & Accession & Gene product & Pathway & $\log 2$ Fold (RNAi/ EV) \\
\hline$J A Z 1$ & Glyma.07G041400.1 & & & 1.848557332 \\
\hline JAZ2 & Glyma.01G204400.1 & & & 3.400343215 \\
\hline JAZ3 & Glyma.09G071600.1 & & & 1.593843195 \\
\hline JAZ4 & Glyma.13G112000.1 & jasmonate ZIM domain- containing protein & Hormone metabolism & 1.575410461 \\
\hline JAZ5 & Glyma.16G010000.1 & & Jasmonate signal transduction & 1.987472879 \\
\hline JAZ6 & Glyma.11G038600.1 & & & 3.403597988 \\
\hline JAZ7 & Glyma.15G179600.1 & & & 1.444590913 \\
\hline JAZ8 & Glyma.17G047700.1 & & & 2.415031607 \\
\hline
\end{tabular}




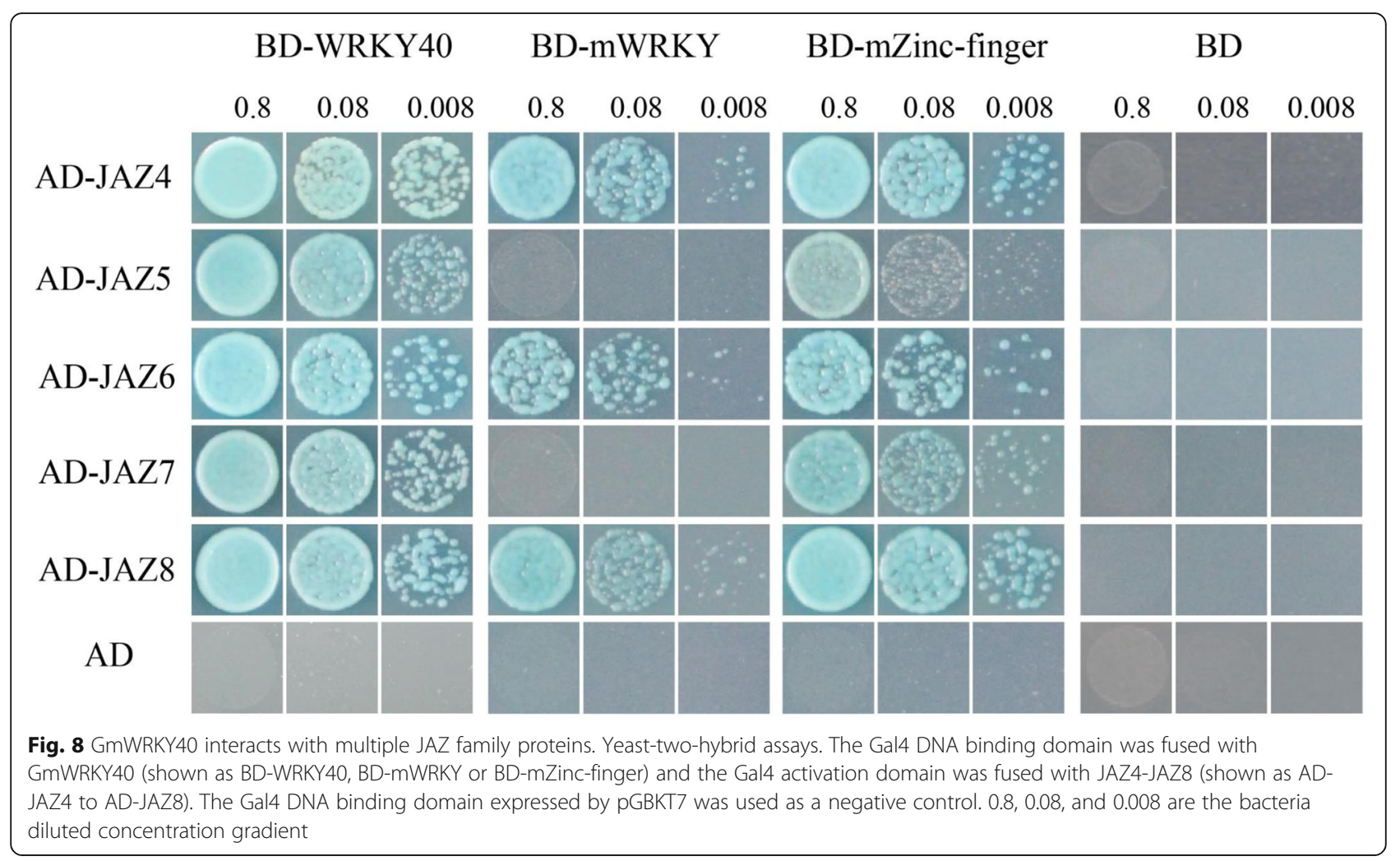

Our findings indicate that GmWRKY40 functions as a positive regulator in soybean plants response to $P$. sojae through modulating hydrogen peroxide accumulation or maybe interact with JAZ proteins. However, functional investigation of GmJAZ overexpression/ RNAi transgenic plants is necessary to further determine the functions of soybean GmWRKY4O in biotic stress resistance. Moreover, further explorations on the identification of GmWRKY40-regulated downstream genes will be useful to clarify the mechanisms of GmWRKY4O in the regulation of soybean response to $P$. sojae. These findings will expand our understanding towards the function of GmWRKY4O and will provide invaluable resources for understanding the molecular interaction between soybean and $P$. sojae.

\section{Materials and methods}

\section{Plant materials, growth conditions and treatments}

Soybean (Glycine. max) seeds of Williams 82 were grown in greenhouse at $25^{\circ} \mathrm{C}$ under a 16-h-light and 8-h-dark photoperiod. Seven-days-old seedlings were infected with $P$. sojae isolate P6497 by hypocotyl inoculation method $[87,88]$. Samples were harvested at 0, 3, 6, 12, 24, 36, 48 and $72 \mathrm{~h}$ post-inoculation (hpi), frozen directly in liquid nitrogen and then stored at $-80^{\circ} \mathrm{C}$ for later use. The soybean seeds and $P$. sojae used in this study provided in the Laboratory of National Center for Soybean Improvement of Nanjing Agricultural University.
For hairy root induction, soybean seeds were surfacesterilized by chlorine gas for $1 \mathrm{~h}$, soaked overnight in sterilized water and then germinated on agar $(0.8 \%)$ medium and grown in a growth chamber $\left(25^{\circ} \mathrm{C}, 16 \mathrm{~h}\right.$ photoperiod) for 6 days. Cotyledons were then collected for Agrobacterium rhizogenes-mediated hairy roots transformation.

For phytohormone treatment, soybean seeds were planted into vermiculite 7 days, then roots were cleaned and submerged in different hormones with the concentration of $100 \mu \mathrm{M}$ methyl jasmonate (MeJA), $2 \mathrm{mM}$ ethylene (ETH), $5 \mathrm{mM}$ salicylic acid (SA) and $50 \mathrm{mM}$ abscisic acid (ABA). Roots were harvested at 0, 1, 3, 6, 12 and $24 \mathrm{~h}$, frozen in liquid nitrogen immediately and stored at $-80^{\circ} \mathrm{C}$ until RNA extraction.

Nicotiana benthamiana plants were grown at $25^{\circ} \mathrm{C}$ with a $16 \mathrm{~h}$ photoperiod in greenhouse. Plants of 5-6 weeks old were used for agroinfiltration.

\section{Phytophthora sojae culture conditions}

P. sojae isolate $\mathrm{P} 6497$ was cultured at $25^{\circ} \mathrm{C}$ on $1.5 \%$ V8 juice agar medium. V8 medium containing $40 \mu \mathrm{g} \mathrm{mL}^{-1}$ geneticin were used to culture the RFP-labeled strain P6497R [89]. For zoospore preparation, cultivate the newly cultured P6497R mycelium in V8 liquid medium, then incubated at $25^{\circ} \mathrm{C}$ in dark for 2 days. The mycelium was then washed several times with sterile $\mathrm{ddH}_{2} \mathrm{O}$ and incubated at $25^{\circ} \mathrm{C}$ in the dark for about $12 \mathrm{~h}$ to 
release zoospores [90]. Finally, the released zoospores were collected to inoculate hairy roots of soybean.

\section{Vectors construction}

To generate GmWRKY4O RNAi construction, the $302 \mathrm{bp}$ cDNA specific fragment of GmWRKY40 gene was amplified by PCR using primers of P12-WRKY40-F and P12WRKY40-R, and then cloned into pDONR221, a Gateway entry vector. Finally, through Gateway LR Clonase reaction, the GmWRKY40 fragment was cloned into pHellsGate12: GFP [21]. The constructed vector was transformed into Agrobacterium rhizogenes K599 strain for further transformation.

For yeast-two-hybrid analysis, the full-length GmWRKY4O cDNA was amplified by PCR using primers of WRKY40BD-F and WRKY40-BD-R, and then cloned into the bait vector pGBKT7 and then transformed into the yeast strain AH109. The full-length JAZ1-JAZ8 coding sequences (CDSs) were cloned into the prey vector pGADT7 and then transformed into the yeast strain Y187. The primers used for yeast two-hybrid are listed in Additional file 3: Table S2.

\section{Subcellular localization of GmWRKY40}

The full coding sequence of GmWRKY40 without termination codon was amplified by primers WRKY40-SCL-F and WRKY40-SCL-R, with Kpn I and Sma I restriction sites respectively, and then constructed into the pBINGFP vector to generate CaMV 35S: GmWRKY40-GFP conctruct. The empty pBIN-GFP vector was used as a control. The both constructs were transformed into Agrobacterium tumefaciens strain GV3101 by electroporation. The validated individual clones were shaken in $4 \mathrm{ml} \mathrm{LB}$ broth (with $50 \mathrm{mg} \mathrm{L}^{-1}$ kanamycin) for $24 \mathrm{~h}$ at $28^{\circ} \mathrm{C}$. Bacteria liquid were washed with $10 \mathrm{mM} \mathrm{MgCl}_{2}$ to a final $\mathrm{OD}_{600}$ of 0.5. The bacterial suspension was infiltrated into the abaxial side of fully expanded 5-6 weeks old tobacco leaves. After infiltration, the plant were kept in the greenhouse $48 \mathrm{~h}$ for inoculation, and then the tissue was strained with DNA-specific nuclear strain 4', 6diamidino-2-phenylindole (DAPI) for $10 \mathrm{~min}$. The GFP signals were detected by a confocal fluorescence microscope (Zeiss, Germany).

\section{Agrobacterium culture and soybean Cotyledon transformation}

The plasmid vectors used for silencing of GmWRKY4O and the empty vector pHellsGate12: GFP were transformed into A. rhizogenes $\mathrm{K} 599$ strain by electroporation. $\mathrm{LB}$ media with $50 \mu \mathrm{g} \cdot \mathrm{mL}^{-1}$ kanamycin were used for select the positive clones, and colony PCR was performed to validate the individual clones. The single-positive colony was shaken in LB broth containing $50 \mu \mathrm{g} \cdot \mathrm{mL}^{-1}$ kanamycin at $28^{\circ} \mathrm{C}$ for $24 \mathrm{~h}$. The bacteria were centrifuged at $4500 \mathrm{rpm}$ for several minutes and suspended in $10 \mathrm{mM} \mathrm{MgCl}_{2}$ (final $\mathrm{OD}_{600}$ is 0.5 ) for soybean cotyledon transformation to obtain soybean hairy roots.

Soybean hairy root transformation was performed according to Graham et al. [91] and Yan et al. [21].

\section{Assay of $P$. sojae infection of soybean hairy roots}

For root inoculation, the transformed hairy roots of soybean were screened under microscope (OLYMPUS MVX10, Japan) by the GFP label in the vector. Then, the roots were inoculated with P6497 mycelia agar according to previous described by Graham et al. [91]. Venire caliper was used to measure the lesion length, and the significance of differences between the control roots and RNAi-GmWRKY4O roots was determined by performing Student's $t$ test.

Detached hairy roots were immersed in the zoospore suspensions (approximately $10^{4}$ zoospore $\mathrm{ml}^{-1}$ ) of $P$. sojae P6497R for $10 \mathrm{~min}$. Inoculated roots were incubated in 0.6\% agar plates in the dark at $25^{\circ} \mathrm{C}$ for $48 \mathrm{~h}$. Disease progression including hyphae extension and oospore development were monitored using a fluorescence microscope (OLYMPUS MVX10, Japan). P. sojae biomass was measured by $\mathrm{qPCR}$ using primers designed to amplify the TEF 1 gene that is specific to P. sojae [21].

\section{Analysis of $\mathrm{H}_{2} \mathrm{O}_{2}$ accumulation}

The $\mathrm{H}_{2} \mathrm{O}_{2}$ burst was assessed by staining infected soybean hairy roots with $3,3^{\prime}$-diaminobenzidine (DAB, 1 $\mathrm{mg} / \mathrm{ml}, \mathrm{pH} 3.8$ ) for $6-8 \mathrm{~h}$ at $25^{\circ} \mathrm{C}$ in the dark. Representative phenotypes were photographed with camera.

The content of $\mathrm{H}_{2} \mathrm{O}_{2}$ was analyzed with a hydrogen peroxide assay kit (Beyotime, S0038) according to the manufacturer protocols. Samples to be tested were placed at room temperature for $30 \mathrm{~min}$ and measured immediately with a spectrometer at a wavelength of 560 $\mathrm{nm}$. Absorbance values were calibrated to a standard curve generated with known concentrations of $\mathrm{H}_{2} \mathrm{O}_{2}$.

\section{Yeast two-hybrid screening and confirmation}

Yeast transformation was performed by the LiAc and polyethylene glycol method, as described in the Yeast Protocols Handbook (Clontech, USA.). Yeast transformants were screened on synthetic dropout nutrient medium with $\mathrm{X}$ - $\alpha$-gal but lacking leucine, tryptophan, histidine, and adenine. Blue colonies indicate a positive interaction between two proteins in yeast.

\section{RNA isolation and quantitative RT-PCR}

Total RNA was extracted using the RNA simple total RNA kit (TIANGEN, China) according to the kit instructions, and total RNA samples were digested with DNase I to remove genomic DNA. RNA was then used to synthesize the first strand of cDNA using reverse 
transcriptase (TaKaRa, Japan) in accordance with the manufacturer's protocol. Real-time PCR was performed using the cDNA and gene-specific primers (Additional file 3: Table S2). Each cDNA was amplified by quantitative PCR using the AceQ qPCR SYBR Green Master Mix (Vazyme, China) with a Light Cycler 480 (Roche, Germany). The soybean GmCons 4 gene was used as internal control in reactions. The $2^{-\triangle \Delta C T}$ comparative CT method was used to estimate the relative expression level of genes. Students' $t$-test was used for statistical analysis.

\section{Supplementary information}

Supplementary information accompanies this paper at https://doi.org/10. 1186/s12870-019-2132-0.

Additional file 1: Figure S1. GFP fluorescence in transgenic soybean hairy roots and analysis of silence efficiency. (A) Green fluorescence observed from a small portion of Agrobacterium-induced hairy roots. Roots were examined under a fluorescence microscope. (B) The expression of GmWRKY40 were validated in each individual hairy root by quantitative RT-PCR. Error bars indicate the standard error. Asterisks indicate statistically significant differences $\left({ }^{* *} P<0.01\right)$. Figure S2. GmWRKY40 participate in soybean basal resistance. (A) The lesion length after $P$. sojae infected with Williams hairy roots. Lesion length was taken at $24 \mathrm{hpi}$. (B) P. sojae biomass was determined by qPCR at 12 and $24 \mathrm{hpi}$ in GmWRKY40 silencing or EV Williams hairy roots. The experiments above were repeated three times along with at least three independent repetitions of the biological experiments. Error bars indicate the standard error. Asterisks indicate statistically significant differences $\left({ }^{* *} P<0.01\right)$. Figure S3. Expression patterns of SA signaling pathway genes in RNAi-GmWRKY40 or EV hairy roots. Transgenic hairy roots were inoculated with zoospore suspension of P. sojae and samples were collected at 0 and $24 \mathrm{~h}$ after inoculation. Gene expression of GmNPR1, GmPR1 $a$ and GmPR5 were analyzed by qRT-PCR. The experiments were repeated three times. Error bars indicate the standard error. Asterisks indicate statistically significant differences (**P $<0.01)$

Additional file 2: Table S1. List of partial differentially expressed genes in RNAi-GmWRKY40 transgenic roots after infection with $P$. sojae when compared to control roots

Additional file 3: Table S2. Primers used in this study

\section{Abbreviations}

ABA: Abscisic acid; APX1: Ascorbate peroxidase 1; CAT1: Catalase 1; DAB: 3 , 3'-diaminobenzidine; DAPI: 4', 6-diamidino-2-phenylindole; ETH: Ethylene; ETI: Effector-triggered immunity; ETS: Effector-triggered susceptibility; EV: Empty vector; JAZ: Jasmonate ZIM-domain; MeJA: Methyl jasmonate; NADPHox: NAD(P) H oxidase; PAMPs: Pathogen-associated molecular patterns; PRRs: Pattern recognition receptors; PTI: PAMP-triggered immunity qRT-PCR: Quantitative reverse transcription PCR; ROS: Reactive oxygen species; SA: Salicylic acid; TFs: Transcription factors

\section{Acknowledgements}

We would like to thank Professor Daolong Dou from Nanjing Agricultural University for providing the yeast strain Y187 and AH109 and vectors pGBKT7 and pGADT7. We also grateful to the laboratory members for help, advice and discussion

\section{Authors' contributions}

XC, QY and NG conceived and designed the experiments. XC, QY, SG and DX performed the experiments. XC, QY and DX analyzed the data. XC drafted the manuscript. NG, SG, HX, HW and JZ helped revise the manuscript. All of the authors read and approved the final manuscript.

\section{Funding}

This work was supported by National Key R\&D Program of China (2017YFD0101500), the Fundamental Research Funds for the Central
Universities (KYZ201811), Genetically Modified Organisms Breeding Major Projects (2016ZX08004002), Modern Agro-industry Technology Research System of China (CARS-04-PS10), Program for Changjiang Scholars and Innovative Research Team in University (PCSIRT_17R55) and Jiangsu Collaborative Innovation Center for Modern Crop Production. The funding agent only provided the financial support and did not involve in the design of the experiment, collection, interpretation and analysis of data and in drafting the manuscript.

\section{Availability of data and materials}

The datasets used and/or analyzed during the current study available from the corresponding author on reasonable request.

Ethics approval and consent to participate

Not applicable.

Consent for publication

Not applicable.

\section{Competing interests}

The authors declare that they have no competing interests.

Received: 14 December 2018 Accepted: 12 November 2019

Published online: 30 December 2019

References

1. Yoshida K, Schuenemann VJ, Cano LM, Pais M, Mishra B, Sharma R, Lanz C, Martin FN, Kamoun S, Krause J, et al. The rise and fall of the Phytophthora infestans lineage that triggered the Irish potato famine. Elife. 2013;2:e00731.

2. Tyler BM. Phytophthora sojae: root rot pathogen of soybean and model oomycete. Mol Plant Pathol. 2007;8(1):1-8.

3. Qutob D, Hraber PT, Sobral BW, Gijzen M. Comparative analysis of expressed sequences in Phytophthora sojae. Plant Physiol. 2000;123(1):243-54.

4. Sugimoto T, Kato M, Yoshida S, Matsumoto I, Kobayashi T, Kaga A, Hajika M, Yamamoto R, Watanabe K, Aino M, et al. Pathogenic diversity of Phytophthora sojae and breeding strategies to develop Phytophthoraresistant soybeans. Breed Sci. 2012;61(5):511-22.

5. Niu JP, Guo N, Sun JT, Li LH, Cao YC, Li SG, Huang JL, Zhao JM, Zhao TJ, Xing $\mathrm{H}$. Fine mapping of a resistance gene RpsHN that controls Phytophthora sojae using recombinant inbred lines and secondary populations. Front Plant Sci. 2017:8:538.

6. Li YP, Sun SL, Zhong C, Wang XM, Wu XF, Zhu ZD. Genetic mapping and development of co-segregating markers of RpsQ, which provides resistance to Phytophthora sojae in soybean. Theor Appl Genet. 2017;130(6):1223-33.

7. Sahoo DK, Abeysekara NS, Cianzio SR, Robertson AE, Bhattacharyya MK. A Novel Phytophthora sojae Resistance Rps12 Gene Mapped to a Genomic Region That Contains Several Rps Genes. PLoS One. 2017;12(1):e0169950.

8. Cheng Y, Ma Q, Ren H, Xia O, Song E, Tan Z, Li S, Zhang G, Nian H. Fine mapping of a Phytophthora-resistance gene RpsWY in soybean (Glycine $\max \mathrm{L}$.) by high-throughput genome-wide sequencing. Theor Appl Genet. 2017;130(5):1041-51

9. Zhong C, Sun S, Li Y, Duan C, Zhu Z. Next-generation sequencing to identify candidate genes and develop diagnostic markers for a novel Phytophthora resistance gene, RpsHC18, in soybean. Theor Appl Genet. 2018;131(3):525-38.

10. Abeysekara NS, Matthiesen RL, Cianzio SR, Bhattacharyya MK, Robertson AE. Novel sources of partial resistance against Phytophthora sojae in soybean PI 399036. Crop Sci. 2016;56(5):2322-35.

11. Lebreton A, Labbe C, De Ronne M, Xue AG, Marchand G, Belanger RR. Development of a simple hydroponic assay to study vertical and horizontal resistance of soybean and Pathotypes of Phytophthora sojae. Plant Dis. 2018;102(1):114-23.

12. Tyler BM. Entering and breaking: virulence effector proteins of oomycete plant pathogens. Cell Microbiol. 2009;11(1):13-20.

13. Kou YJ, Wang SP. Broad-spectrum and durability: understanding of quantitative disease resistance. Curr Opin Plant Biol. 2010;13(2):181-5.

14. St Clair DA. Quantitative Disease Resistance and Quantitative Resistance Loci in Breeding. Annu Rev Phytopathol. 2010;48:247-68.

15. Tooley PW, Grau CR. Field characterization of rate-reducing resistance to Phytophthora-Megasperma F Sp Glycinea in soybean. Phytopathology. 1984;74(10):1201-8. 
16. Mideros S, Nita M, Dorrance AE. Characterization of components of partial resistance, Rps2, and root resistance to Phytophthora sojae in soybean. Phytopathology. 2007;97(5):655-62.

17. Wang HH, Wijeratne A, Wijeratne S, Lee S, Taylor CG, St Martin SK, McHale L, Dorrance AE. Dissection of two soybean QTL conferring partial resistance to Phytophthora sojae through sequence and gene expression analysis. BMC Genomics. 2012;13:428.

18. Vega-Sanchez ME, Redinbaugh MG, Costanzo S, Dorrance AE. Spatial and temporal expression analysis of defense-related genes in soybean cultivars with different levels of partial resistance to Phytophthora sojae. Physiol Mol Plant Pathol. 2005;66(5):175-82.

19. Zhou LC, Mideros SX, Bao L, Hanlon R, Arredondo FD, Tripathy S, Krampis K, Jerauld A, Evans C, St Martin SK, et al. Infection and genotype remodel the entire soybean transcriptome. BMC Genomics. 2009;10:49.

20. Schneider R, Rolling W, Song QJ, Cregan P, Dorrance AE, McHale LK. Genomewide association mapping of partial resistance to Phytophthora sojae in soybean plant introductions from the Republic of Korea. BMC Genomics. 2016;17:607.

21. Yan Q, Cui X, Su L, Xu N, Guo N, Xing H, Dou D. GmSGT1 is differently required for soybean $R p s$ genes-mediated and basal resistance to Phytophthora sojae. Plant Cell Rep. 2014;33(8):1275-88.

22. Gurr SJ, Rushton PJ. Engineering plants with increased disease resistance: what are we going to express? Trends Biotechnol. 2005;23(6):275-82.

23. Yan Q, Si J, Cui X, Peng H, Jing M, Chen X, Xing H, Dou D. GmDAD1, a Conserved Defender Against Cell Death 1 (DAD1) From Soybean, Positively Regulates Plant Resistance Against Phytophthora Pathogens. Front Plant Sci. 2019;10:107.

24. Zhang C, Gao H, Li R, Han D, Wang L, Wu J, Xu P, Zhang S. GmBTB/POZ, a novel $\mathrm{BTB} / \mathrm{POZ}$ domain-containing nuclear protein, positively regulates the response of soybean to Phytophthora sojae infection. Mol Plant Pathol. 2019;20(1):78-91.

25. Cheng Q, Dong L, Gao T, Liu T, Li N, Wang L, Chang X, Wu J, Xu P, Zhang S. The bHLH transcription factor GmPIB1 facilitates resistance to Phytophthora sojae in Glycine max. J Exp Bot. 2018;69(10):2527-41.

26. Dong L, Cheng Y, Wu J, Cheng Q, Li W, Fan S, Jiang L, Xu Z, Kong F, Zhang $D$, et al. Overexpression of GmERF5, a new member of the soybean EAR motif-containing ERF transcription factor, enhances resistance to Phytophthora sojae in soybean. J Exp Bot. 2015;66(9):2635-47.

27. Zhao Y, Chang X, Qi D, Dong L, Wang G, Fan S, Jiang L, Cheng Q, Chen X, Han $D$, et al. A novel soybean ERF transcription factor, GmERF113, Increases Resistance to Phytophthora sojae Infection in Soybean. Front Plant Sci. 2017:8:299.

28. Suen TC, Hung MC. Multiple cis- and trans-acting elements involved in regulation of the neu gene. Mol Cell Biol. 1990;10(12):6306-15.

29. Kawaoka A, Kawamoto T, Sekine M, Yoshida K, Takano M, Shinmyo A. A Cisacting element and a Trans-acting factor involved in the wound-induced expression of a horseradish-peroxidase gene. Plant J. 1994;6(1):87-97.

30. Ulker B, Somssich IE. WRKY transcription factors: from DNA binding towards biological function. Curr Opin Plant Biol. 2004;7(5):491-8.

31. Eulgem T, Somssich IE. Networks of WRKY transcription factors in defense signaling. Curr Opin Plant Biol. 2007;10(4):366-71.

32. Eulgem T, Rushton PJ, Robatzek S, Somssich IE. The WRKY superfamily of plant transcription factors. Trends Plant Sci. 2000;5(5):199-206.

33. Rushton PJ, Somssich IE, Ringler P, Shen QJ. WRKY transcription factors. Trends Plant Sci. 2010;15(5):247-58.

34. Chen F, Hu Y, Vannozzi A, Wu KC, Cai HY, Qin Y, Mullis A, Lin ZG, Zhang LS. The WRKY transcription factor family in model plants and crops. Crit Rev Plant Sci. 2017;36(5-6):311-35.

35. Birkenbihl RP, Kracher B, Roccaro M, Somssich IE. Induced genome-wide binding of three Arabidopsis WRKY transcription factors during early MAMPtriggered immunity. Plant Cell. 2017;29(1):20-38.

36. Hwang SH, Kwon SI, Jang JY, Fang IL, Lee H, Choi C, Park S, Ahn I, Bae SC, Hwang DJ. OsWRKY51, a rice transcription factor, functions as a positive regulator in defense response against Xanthomonas oryzae pv. oryzae. Plant Cell Rep. 2016;35(9):1975-85.

37. Zhang YJ, Wang LJ. The WRKY transcription factor superfamily: its origin in eukaryotes and expansion in plants. BMC Evol Biol. 2005:5:1

38. Bencke-Malato M, Cabreira C, Wiebke-Strohm B, Bucker-Neto L, Mancini E, Osorio MB, Homrich MS, Turchetto-Zolet AC, De Carvalho MCCG, Stolf R, et al. Genome-wide annotation of the soybean WRKY family and functional characterization of genes involved in response to Phakopsora pachyrhizi infection. BMC Plant Biol. 2014;14:236.

39. Chen $\mathrm{CH}$, Chen ZX. Potentiation of developmentally regulated plant defense response by AtWRKY18, a pathogen-induced Arabidopsis transcription factor. Plant Physiol. 2002;129(2):706-16.
40. Oh SK, Baek KH, Park JM, Yi SY, Yu SH, Kamoun S, Choi D. Capsicum annuum WRKY protein CaWRKY1 is a negative regulator of pathogen defense. New Phytol. 2008;177(4):977-89.

41. Li J, Brader G, Palva ET. The WRKY70 transcription factor: a node of convergence for jasmonate-mediated and salicylate-mediated signals in plant defense. Plant Cell. 2004;16(2):319-31.

42. Birkenbihl RP, Diezel C, Somssich IE. Arabidopsis WRKY33 is a key transcriptional regulator of hormonal and metabolic responses toward Botrytis cinerea infection. Plant Physiol. 2012;159(1):266-85.

43. Shimono M, Sugano S, Nakayama A, Jiang CJ, Ono K, Toki S, Takatsuji H. Rice WRKY45 plays a crucial role in benzothiadiazole-inducible blast resistance. Plant Cell. 2007;19(6):2064-76.

44. Hwang SH, Yie SW, Hwang DJ. Heterologous expression of OsWRKY6 gene in Arabidopsis activates the expression of defense related genes and enhances resistance to pathogens. Plant Sci. 2011;181(3):316-23.

45. Dang FF, Wang YN, Yu L, Eulgem T, Lai Y, Liu ZQ, Wang X, Qiu AL, Zhang TX, Lin J, et al. CaWRKY40, a WRKY protein of pepper, plays an important role in the regulation of tolerance to heat stress and resistance to Ralstonia solanacearum infection. Plant Cell Environ. 2013;36(4):757-74.

46. Judelson HS, Blanco FA. The spores of Phytophthora: weapons of the plant destroyer. Nat Rev Microbiol. 2005;3(1):47-58.

47. Adachi H, Nakano T, Miyagawa N, Ishihama N, Yoshioka M, Katou Y, Yaeno T, Shirasu K, Yoshioka H. WRKY transcription factors phosphorylated by MAPK regulate a plant immune NADPH oxidase in Nicotiana benthamiana. Plant Cell. 2015;27(9):2645-63.

48. Yogendra KN, Dhokane D, Kushalappa AC, Sarmiento F, Rodriguez E, Mosquera T. StWRKY8 transcription factor regulates benzylisoquinoline alkaloid pathway in potato conferring resistance to late blight. Plant Sci. 2017;256:208-16.

49. Cui J, Xu P, Meng J, Li J, Jiang N, Luan Y. Transcriptome signatures of tomato leaf induced by Phytophthora infestans and functional identification of transcription factor SpWRKY3. Theor Appl Genet. 2018;131(4):787-800.

50. Li JB, Luan YS, Liu Z. Overexpression of SpWRKY1 promotes resistance to Phytophthora nicotianae and tolerance to salt and drought stress in transgenic tobacco. Physiol Plant. 2015;155(3):248-66.

51. Zhou QY, Tian AG, Zou HF, Xie ZM, Lei G, Huang J, Wang CM, Wang HW, Zhang JS, Chen SY. Soybean WRKY-type transcription factor genes, GmWRKY13, GmWRKY21, and GmWRKY54, confer differential tolerance to abiotic stresses in transgenic Arabidopsis plants. Plant Biotechnol J. 2008;6(5):486-503.

52. Yang Y, Chi YJ, Wang Z, Zhou Y, Fan BF, Chen ZX. Functional analysis of structurally related soybean GmWRKY58 and GmWRKY76 in plant growth and development. J Exp Bot. 2016;67(15):4727-42.

53. Wang Z, Li PF, Yang Y, Chi YJ, Fan BF, Chen ZX. Expression and functional analysis of a novel Group of Legume-specific WRKY and Exo70 protein variants from soybean. Sci Rep. 2016;6:32090.

54. Fan SJ, Dong LD, Han D, Zhang F, Wu JJ, Jiang LY, Cheng Q, Li RP, Lu WC, Meng FS, et al. GmWRKY31 and GmHDL56 enhances resistance to Phytophthora sojae by regulating defense-related gene expression in soybean. Front Plant Sci. 2017:8:781.

55. Subramanian S, Graham MY, Yu O, Graham TL. RNA interference of soybean isoflavone synthase genes leads to silencing in tissues distal to the transformation site and to enhanced susceptibility to Phytophthora sojae. Plant Physiol. 2005;137(4):1345-53.

56. Bari $\mathrm{R}$, Jones J. Role of plant hormones in plant defence responses. Plant Mol Biol. 2009;69(4):473-88.

57. Wong J, Gao L, Yang Y, Zhai J, Arikit S, Yu Y, Duan S, Chan V, Xiong Q, Yan $J$, et al. Roles of small RNAs in soybean defense against Phytophthora sojae infection. Plant J. 2014;79(6):928-40.

58. Mittler R, Vanderauwera S, Gollery M, Van Breusegem F. Reactive oxygen gene network of plants. Trends Plant Sci. 2004;9(10):490-8.

59. Sagi M, Fluhr R. Superoxide production by plant homologues of the gp91 ${ }^{\text {phox }}$ NADPH oxidase. Modulation of activity by calcium and by tobacco mosaic virus infection. Plant Physiol. 2001;126(3):1281-90.

60. Takahashi H, Chen ZX, Du H, Liu YD, Klessig DF. Development of necrosis and activation of disease resistance in transgenic tobacco plants with severely reduced catalase levels. Plant J. 1997;11(5):993-1005.

61. Noctor $\mathrm{G}$, Foyer $\mathrm{CH}$. Ascorbate and glutathione: keeping active oxygen under control. Annu Rev Plant Physiol. 1998;49:249-79.

62. Eulgem T, Weigman VJ, Chang HS, McDowell JM, Holub EB, Glazebrook J, Zhu T, Dangl JL. Gene expression signatures from three genetically separable resistance gene signaling pathways for downy mildew resistance. Plant Physiol. 2004;135(2):1129-44. 
63. Kim KC, Lai ZB, Fan BF, Chen ZX. Arabidopsis WRKY38 and WRKY62 transcription factors interact with histone Deacetylase 19 in basal defense. Plant Cell. 2008;20(9):2357-71.

64. Yokotani N, Sato Y, Tanabe S, Chujo T, Shimizu T, Okada K, Yamane H, Shimono M, Sugano S, Takatsuji H, et al. WRKY76 is a rice transcriptional repressor playing opposite roles in blast disease resistance and cold stress tolerance. J Exp Bot. 2013;64(16):5085-97.

65. Cheng HT, Liu HB, Deng Y, Xiao JH, Li XH, Wang SP. The WRKY45-2 WRKY13 WRKY42 transcriptional regulatory Cascade is required for Rice resistance to fungal pathogen. Plant Physiol. 2015;167(3):1087-99.

66. Meng Y, Wise RP. HvWRKY10, HvWRKY19, and HvWRKY28 regulate Mlatriggered immunity and basal defense to barley powdery mildew. Mol Plant-Microbe Interact. 2012;25(11):1492-505.

67. Yu F, Huaxia Y, Lu W, Wu C, Cao X, Guo X. GhWRKY15, a member of the WRKY transcription factor family identified from cotton (Gossypium hirsutum L.), is involved in disease resistance and plant development. BMC Plant Biol. 2012;12:144.

68. Ishihama N, Yamada R, Yoshioka M, Katou S, Yoshioka H. Phosphorylation of the Nicotiana benthamiana WRKY8 transcription factor by MAPK functions in the defense response. Plant Cell. 2011;23(3):1153-70.

69. Pandey AK, Yang CL, Zhang CQ, Graham MA, Horstman HD, Lee Y, Zabotina OA, Hill JH, Pedley KF, Whitham SA. Functional analysis of the Asian soybean rust resistance pathway mediated by Rpp2. Mol Plant-Microbe Interact. 2011;24(2):194-206.

70. Zhang CQ, Grosic S, Whitham SA, Hill JH. The requirement of multiple defense genes in soybean Rsv1-mediated extreme resistance to Soybean mosaic virus. Mol Plant-Microbe Interact. 2012;25(10):1307-13.

71. Lin F, Zhao MX, Baumann DD, Ping JQ, Sun LJ, Liu YF, Zhang B, Tang ZX, Hughes E, Doerge RW, et al. Molecular response to the pathogen Phytophthora sojae among ten soybean near isogenic lines revealed by comparative transcriptomics. BMC Genomics. 2014;15:18.

72. Peng Y, Bartley LE, Chen XW, Dardick C, Chern MS, Ruan R, Canlas PE, Ronald PC. OsWRKY62 is a negative regulator of basal and Xa21mediated defense against Xanthomonas oryzae pv. oryzae in rice. Mol Plant. 2008;1(3):446-58.

73. Pieterse CMJ, Leon-Reyes A, Van der Ent S, Van Wees SCM. Networking by small-molecule hormones in plant immunity. Nat Chem Biol. 2009;5(5):308-16.

74. Jiang YJ, Yu DQ. WRKY transcription factors: links between phytohormones and plant processes. Sci China Life Sci. 2015;58(5):501-2.

75. Chen LG, Zhang LP, Li DB, Wang F, Yu DQ. WRKY8 transcription factor functions in the TMV-cg defense response by mediating both abscisic acid and ethylene signaling in Arabidopsis. Proc Natl Acad Sci U S A. 2013; 110(21):E1963-71

76. Wi SJ, Ji NR, Park KY. Synergistic biosynthesis of biphasic ethylene and reactive oxygen species in response to Hemibiotrophic Phytophthora parasitica in tobacco plants. Plant Physiol. 2012;159(1):251-65.

77. Thordal-Christensen $\mathrm{H}$, Zhang ZG, Wei YD, Collinge DB. Subcellular localization of $\mathrm{H}_{2} \mathrm{O}_{2}$ in plants. $\mathrm{H}_{2} \mathrm{O}_{2}$ accumulation in papillae and hypersensitive response during the barley-powdery mildew interaction. Plant J. 1997;11(6):1187-94.

78. Shetty NP, Jorgensen HJL, Jensen JD, Collinge DB, Shetty HS. Roles of reactive oxygen species in interactions between plants and pathogens. Eur J Plant Pathol. 2008;121(3):267-80.

79. Foreman J, Demidchik V, Bothwell JHF, Mylona P, Miedema H, Torres MA, Linstead P, Costa S, Brownlee C, Jones JDG, et al. Reactive oxygen species produced by NADPH oxidase regulate plant cell growth. Nature. 2003: 422(6930):442-6

80. Chini A, Fonseca S, Fernandez G, Adie B, Chico JM, Lorenzo O, GarciaCasado G, Lopez-Vidriero I, Lozano FM, Ponce MR, et al. The JAZ family of repressors is the missing link in jasmonate signalling. Nature. 2007; 448(7154):666-U664.

81. Thines B, Katsir L, Melotto M, Niu Y, Mandaokar A, Liu G, Nomura K, He SY, Howe GA, Browse J. JAZ repressor proteins are targets of the SCF (COI1) complex during jasmonate signalling. Nature. 2007:448(7154):661-5.

82. Pauwels L, Goossens A. The JAZ proteins: a crucial interface in the jasmonate signaling cascade. Plant Cell. 2011;23(9):3089-100.

83. He X, Zhu LF, Wassan GM, Wang YJ, Miao YH, Shaban M, Hu HY, Sun H, Zhang XL. GhJAZ2 attenuates cotton resistance to biotic stresses via the inhibition of the transcriptional activity of GhbHLH171. Mol Plant Pathol. 2018;19(4):896-908.

84. Kazan K, Manners JM. JAZ repressors and the orchestration of phytohormone crosstalk. Trends Plant Sci. 2012;17(1):22-31.
85. Thatcher LF, Cevik V, Grant M, Zhai B, Jones JD, Manners JM, Kazan K. Characterization of a JAZ7 activation-tagged Arabidopsis mutant with increased susceptibility to the fungal pathogen Fusarium oxysporum. J Exp Bot. 2016;67(8):2367-86.

86. Jiang YJ, Yu DQ. The WRKY57 transcription factor affects the expression of Jasmonate ZIM-domain genes transcriptionally to compromise Botrytis cinerea resistance. Plant Physiol. 2016;171(4):2771-82.

87. Sun $\mathrm{S}$, Wu XL, Zhao JM, Wang YC, Tang QH, Yu DY, Gai JY, Xing $H$. Characterization and mapping of RpsYu25, a novel resistance gene to Phytophthora sojae. Plant Breed. 2011;130(2):139-43.

88. Sun J, Li L, Zhao J, Huang J, Yan Q, Xing H, Guo N. Genetic analysis and fine mapping of RpsJS, a novel resistance gene to Phytophthora sojae in soybean [Glycine max (L.) Merr]. Theor Appl Genet. 2014;127(4):913-9.

89. Xiong Q, Ye W, Choi D, Wong J, Qiao Y, Tao K, Wang Y, Ma W. Phytophthora suppressor of RNA silencing 2 is a conserved RxLR effector that promotes infection in soybean and Arabidopsis thaliana. Mol PlantMicrobe Interact. 2014;27(12):1379-89.

90. Zhang M, Lu J, Tao K, Ye W, Li A, Liu X, Kong L, Dong S, Zheng X, Wang Y. A Myb transcription factor of Phytophthora sojae, regulated by MAP kinase PsSAK1, is required for zoospore development. PLOS One. 2012;7(6):e40246.

91. Graham TL, Graham MY, Subramanian S, Yu O. RNAi silencing of genes for elicitation or biosynthesis of 5-deoxyisoflavonoids suppresses race-specific resistance and hypersensitive cell death in Phytophthora sojae infected tissues. Plant Physiol. 2007;144(2):728-40.

\section{Publisher's Note}

Springer Nature remains neutral with regard to jurisdictional claims in published maps and institutional affiliations.
Ready to submit your research? Choose BMC and benefit from:

- fast, convenient online submission

- thorough peer review by experienced researchers in your field

- rapid publication on acceptance

- support for research data, including large and complex data types

- gold Open Access which fosters wider collaboration and increased citations

- maximum visibility for your research: over $100 \mathrm{M}$ website views per year

At $\mathrm{BMC}$, research is always in progress.

Learn more biomedcentral.com/submissions 